\title{
Relapsing polychondritis: a pediatric series of ten patients
} A Belot*1, C Job-Deslandre 5 , S Boudjemaa ${ }^{3}$, A Duquesne ${ }^{1}, \mathrm{~N}$
Costedoat Chalumeau ${ }^{2}$, B Wechsler ${ }^{2}$, JC Piette ${ }^{2}$ and R Cimaz

Address: ${ }^{1}$ Hopital Femme Mère Enfant, Lyon, France, ${ }^{2}$ Hopital de la Pitié Salpetrière, Paris, France, ${ }^{3}$ Hopital d'enfant Armand Trousseau, Paris, France, ${ }^{4}$ Ospedale Pediatrico Meyer, Firenze, Italy and ${ }^{5}$ Hopital Saint Vincent de Paul, Paris, France

${ }^{*}$ Corresponding author

from I5th Paediatric Rheumatology European Society (PreS) Congress

London, UK. 14-17 September 2008

Published: 15 September 2008

Pediatric Rheumatology 2008, 6(Suppl I):P235 doi:I0.I I86/I546-0096-6-SI-P235

This abstract is available from: http://www.ped-rheum.com/content/6/SI/P235

(c) 2008 Belot et al; licensee BioMed Central Ltd.

\section{Background}

Relapsing polychondritis (RP) is a disease of unknown etiology and is characterized by cartilage inflammation. RP can be isolated or secondary to different diseases (vasculitis, myelodysplastic syndrome, rheumatoid arthritis or systemic lupus erythematosus). While the clinical picture of $\mathrm{RP}$ in adults is well known, $\mathrm{RP}$ in childhood remains poorly described.

\section{Materials and methods}

We retrospectively collected data from 10 patients followed in three French hospitals for relapsing polychondritis with an age at onset before 18 years.

\section{Results}

The mean age for the first symptoms was $8.6 \pm 5.7$ years (range 1.8-17). Symptoms included joint pain (10/10), ocular inflammation (4/9) and chondritis which concerned ears (10/10), nose (6/10) and larynx (5/10). Laboratory tests showed positive ANA in two patients $(>1: 160)$, absence of anticartilage antibodies, and a slight increase of the erythrocyte sedimentation rate in 5/9 patients (mean $=25 \mathrm{~mm}$ ) Biopsy was performed in only two patients and showed perichondritis with eosinophilic and mononuclear infiltration for Pt2 while it was normal in Pt7. Treatment mainly consisted in NSAIDs $(7 / 10)$, steroids $(8 / 10)$, and methotrexate $(6 / 10)$ and more rarely hydroxychloroquine $(2 / 10)$, colchicine $(1 / 10)$, dapsone $(3 / 10)$, salazopyrine $(2 / 10)$, azathioprine $(1 / 10)$.
Pt 1 died of aortic insufficiency and others presented recurrent flares with chronic destroying chondritis.

\section{Conclusion}

Pediatric RP shares the main clinical features of its adult counterpart, even if secondary forms seem to be less frequent. Laboratory findings are nonspecific, and biopsies may be unnecessary. Evolution is marked by chronic destroying chondritis and could lead to fatal lesions despite immunosuppressive treatment. 